\title{
Space Charge Wave with Broad Frequency Spectrum Formation in Transit Section of Klystron-type Two-stream FEL with Helical Electron Beam
}

\author{
A.V. Lysenko ${ }^{1, *}$, I.I. Volk ${ }^{1}$, G.A. Oleksiienko ${ }^{1}$, A.A. Shmat'ko² \\ ${ }^{1}$ Sumy State University, 2, Rimsky-Korsakov St., 40007 Sumy, Ukraine \\ ${ }^{2}$ V.N. Karazin Kharkiv National University, 4, Svobody Sq., 61022 Kharkiv, Ukraine
}

(Received 23 July 2019; revised manuscript received 21 October 2019; published online 25 October 2019)

\begin{abstract}
In the cubic non-linear approximation framework, the analysis of space charge wave formation with a wide frequency spectrum in helical two-velocity electron beams was performed. It was shown that the formation of a space charge wave with wide frequency spectrum in this kind of beams occurs on condition that the wave first harmonic frequency is much less than the two-stream instability critical frequency. We demonstrated that due to the linearity of the growing space charge wave dispersion characteristic, the condition of the three-wave parametric resonant interactions in helical two-stream relativistic electron beam fulfills for a significant number of such wave's harmonics which frequencies are less than the critical frequency. Due to these resonances, the excitation of multiharmonic space charge wave occurs. This wave is amplified due to both the three-wave parametric resonances and the two-stream instability mechanism. As a result, the multiharmonic space charge wave forms, and its spectrum width is defined by the $1^{\text {st }}$ harmonic frequency and the two-stream instability critical frequency. It is demonstrated that the frequency spectrum width of the multiharmonic space charge wave increases with the increase of the electrons input angle with respect to the longitudinal focusing magnetic field and it exceeds the frequency spectrum width of such waves in straight electron beams. It is also found out that the space charge wave saturation length in a helical electron beam is two and more times less than in straight electron beams. Therefore, the devices using two-stream helical relativistic electron beams would have less longitudinal dimensions. We proposed to use helical two-stream relativistic electron beams in multiharmonic two-stream superheterodyne freeelectron lasers in order to increase the frequency spectrum width and to decrease the device's longitudinal dimensions compared with devices using straight electron beams.
\end{abstract}

Keywords: Two-stream instability, Two-stream superheterodyne free-electron lasers, Helical electron beam.

\section{INTRODUCTION}

Owing to the two-stream instability, the two-stream superheterodyne free-electron lasers (TSFELs) are characterized by exclusively high amplification properties in millimeter-infrared wavelength band [1-11]. However, single-section TSFEL amplifiers have a pronounced tendency to self-excitation due to extremely high amplification level. This problem can be effectively solved by use of the klystron-type TSFEL schemes [1]. The main advantage of this design is the very deep input-output decoupling. It fully suppresses the abovementioned self-excitation in single-section TSFELs.

In the majority of works devoted to TSFEL klystrons and TSFEL in general, only monochromatic operation modes are investigated. In such modes the space charge wave (SCW) is excited on the frequency having maximal amplification due to the two-stream instability [1-11]. Lately, there are also works investigating multiharmonic operation modes of TSFELs [1, 12, 13]. In these studies, multiharmonic TSFELs capable of powerful ultrashort electromagnetic field cluster formation and able to create powerful multiharmonic signal with a wide frequency spectrum are investigated. In this connection, there is a task to find TSFEL operation modes in which effective generation of electromagnetic waves with a wide frequency spectrum takes place.
A multiharmonic SCW is the source of multiharmonic waves in TSFELs. Previously performed researches $[1,12,13]$ showed that $\mathrm{SCW}$ with a broad frequency spectrum (tens and more harmonics) is excited in straight two-stream relativistic electron beams, if the frequency of the first harmonic of SCW that grows due to the two-stream instability is much less than the two-stream instability critical frequency. The excitement of such SCW is caused by two factors.

Firstly, the SCW growing due to the two-stream instability is characterized by the quasilinear dispersion characteristic. Therefore, the conditions of parametric resonance between the harmonics of such a wave are satisfied for the plurality of harmonics, i.e. plural three-wave parametric resonant interactions take place. The excitement of higher SCW harmonics happens because of such interactions. Frequencies of such harmonics do not exceed critical frequency of the twostream instability.

Secondly, since the frequency of the first SCW harmonic is much less than the critical frequency of the two-stream instability, the harmonics excited due to the plural resonant interactions are also amplified due to the two-stream instability. As a result of superposition of plural resonant interactions and the two-stream instability, the powerful multiharmonic SCW with a broad frequency spectrum, which can be a source of multiharmonic waves in multiharmonic TSFELs, forms.

\footnotetext{
*lysenko_@ukr.net
} 
Further search of the multiharmonic operation modes has revealed that excitation of multiharmonic SCWs happens more effectively in helical two-stream relativistic electron beams [13]. In the framework of the small-signal approximation it was found out that in helical two-velocity relativistic electron beams the growth rates of the two-stream instability are higher than in the straight beams. The critical frequency of the two-stream instability also increases which is the evidence of possibility to form multiharmonic SCW with broader frequency spectrum. But some questions remained uncertain: what are the saturation levels, the spectral characteristics of SCW, the SCW dynamics in cubic nonlinear approximation. This work is devoted to the solution of these questions.

\section{MODEL. BASIC EQUATIONS}

The simplest variant of scheme of the klystron TSFEL amplifier is shown in Fig. 1.

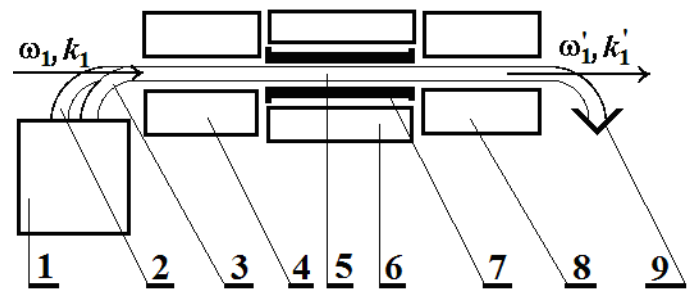

Fig. 1 - The model of klystron TSFEL amplifier. Here: 1 is the two-beam electron accelerator, 2 is the first helical electron beam, 3 is the second helical electron beam, 4 is the first pumping system, 5 is the two-stream electron beam, 6 is the transit section, 7 is the absorber system, 8 is the second pumping system, 9 is the electron collector, $\omega_{1}, k_{1}$ are the amplified electromagnetic wave signal (frequency and wave number, respectively)

The device works in the following manner. Twobeam electron accelerator 1 generates two one-velocity helical relativistic electron beams 2 and 3, respectively. Both these beams are directed at the same input of the first pumping system 4 . Then they form joint twovelocity helical electron beam 5 . Electromagnetic signal $\omega_{1}, k_{1}$ (in the form of an amplified electromagnetic wave) is directed in the same input of the first pumping system 4. Two-velocity electron beam 5 is weakdensity-modulated as a result of the nonlinear parametric interaction of the electromagnetic wave $\omega_{1}, k_{1}$ with the first pumping system 4 and a SCW. So, further (within transit section 6) electron beam 5 propagates being modulated by frequency $\omega_{3}$ (frequencies $\omega_{1}$ and $\omega_{3}$ can be different in the general case). This means that initial (input) signal $\omega_{1}, k_{1}$ transforms from the electromagnetic form in the electron-wave one in the first pumping system.

The two-stream instability develops in electron beam 5 within transit section 6 . Amplification maximum of the longitudinal electron waves in this case attains for the waves with some optimal frequency $\omega_{\text {opt }}$ (9) $[1,8,11-13]$. The key point of the discussed design is that the modulation frequency $\omega_{3}$ is much smaller than the optimal frequency $\omega_{\text {opt }}$, at which SCW has maximal growth increment due to the two-stream instability. In this case, the intensive generation of higher harmonics occurs due to the plural three-wave parametric resonant interactions. Higher harmonics are further amplified due to the two-stream instability. The formation of SCW with a broad frequency spectrum containing abnormal region in which higher harmonics are characterized by higher amplitudes occurs. So, the input signal $\omega_{1}, k_{1}$ exists in transit section 6 in the form of a multiharmonic electron SCW. At the same time, absorber system 7 absorbs the initial (input) electromagnetic signal $\omega_{1}, k_{1}$. Thus, the modulated electron beam with a multiharmonic SCW enters the input of the second pumping system 8 . The input electromagnetic signal $\omega_{1}, k_{1}$ further is absorbed in system 7 .

The generation of the output electromagnetic signal $\omega_{1}^{\prime}, k_{1}^{\prime}$ occurs within the second pumping system 8 . This takes place due to the nonlinear interaction of modulated electron beam 5 with relevant pumping field of the second pumping system 8. This means that the back transformation from the electron-wave-form $\omega_{3}, k_{3}$ into the electromagnetic one $\omega_{1}^{\prime}, k_{1}^{\prime}$ takes place within the work bulk of the second pumping system 8 . The worked off electron beam is collected by electron collector 9. The amplified electromagnetic signal is got from the system output.

Thus, a main merit of the klystron TSFEL is an original decoupling on a signal electromagnetic wave. It is realized by the transit section 6 . Due to this, the TSFEL klystrons are characterized by rather high level of input-output decoupling with respect to the signal wave.

The present work is devoted to the analysis of plural resonant interactions of growing SCW harmonics in the transit section 6 of the TSFEL of klystron type with helical electron beam. We consider the following model of the two-velocity helical electron beam in the transit section 6. The helical two-stream relativistic electron beam consists of two partial interpenetrating electron streams with close values of relativistic velocities $v_{1}$, $v_{2}\left(v_{1}-v_{2}<<v_{1}, v_{2}\right)$. The beam is injected at an angle $\alpha$ to the focusing magnetic field $\mathbf{B}_{0}$ and moves along the helical trajectory. We take partial plasma frequencies of beams as equal $\omega_{\mathrm{p}, 1}=\omega_{\mathrm{p}, 2}$. We consider that the space charge of the beam is compensated by an ion background. We talk about the situation when the transversal dimensions of the model are much bigger than the wavelengths propagating in the investigated system. In this case, the beam can be considered as homogenous and we can neglect its borders influence on the wave dynamics.

The SCW of the helical two-stream superheterodyne electron beam is taken multiharmonic. The electric field of this wave has the form

$$
E_{\mathrm{z}}=\sum_{m=1}^{N}\left[E_{m} \exp \left(\mathrm{i} p_{m}\right)+c . c .\right],
$$

where $N$ is the maximal harmonic number considered 
in the problem; $p_{m}=\omega_{m} t-k_{m} z$ is the phase of $m^{\text {th }}$ SCW harmonic, $\omega_{m}=m \cdot \omega_{1}, k_{m}$ are its frequency and wavenumber respectively, the axis $Z$ is directed along the focusing magnetic field $\mathbf{B}_{0}$.

In order to numerically analyze the processes described above, we use the quasihydrodynamic equation, the continuity equation and Maxwell's equations as initial. We utilize methods of hierarchic theory of oscillations and waves to solve these equations [1]. This approach is based on Krylov-Bogoliubov method [1] for the asymptotic integration of the differential equations.

We consider the case when the electron collision and thermal spread can be neglected. We investigate the model, in which all values depend only on longitudinal coordinate $z$ and time $t$. Then, the relativistic quasihydrodynamic equation, the continuity equation and Maxwell's equations can be presented in the following form:

$$
\begin{gathered}
\left(\frac{\partial}{\partial t}+\mathrm{v}_{q z} \frac{\partial}{\partial z}\right) \mathrm{v}_{q z}=\frac{e}{m_{\mathrm{e}} \gamma_{q}} E_{z}\left(1-\frac{\mathrm{v}_{q z}^{2}}{c^{2}}\right), \\
\left(\frac{\partial}{\partial t}+\mathrm{v}_{q z} \frac{\partial}{\partial z}\right) n_{q}=-n_{q} \frac{\partial \mathrm{v}_{q z}}{\partial z}, \\
\frac{\partial E_{\mathrm{z}}}{\partial z}=4 \pi \sum_{q=1}^{2} e n_{q} .
\end{gathered}
$$

Here $v_{q z}, \gamma_{q}=\left(1-\left(v_{q} / c\right)^{2}\right)^{-1 / 2}$ are the velocity projection on axis $Z$ and the relativistic factor of the $q^{\text {th }}$ beam respectively, $c$ is the speed of light, $e, m_{\mathrm{e}}$ are the electron charge and mass respectively, $n_{\mathrm{q}}$ is the electron concentration of the $q^{\text {th }}$ beam.

As it is known, the solution of the (2)-(4) consists of three formally independent stages: solution of the motion problem (2) of two-stream relativistic electron beam in given electromagnetic fields; solution of the continuity equation (3) considering that we already know the velocities of electron beam; solution of the excitation problem of electromagnetic fields (4) considering velocities and concentrations as known values.

We solve the motion problem and the continuity equation by means of the modernized method of averaged characteristics [1,14]. For electromagnetic field excitation problem solution we utilize the method of slowly varying amplitudes. The features of plural three-wave parametric resonant interactions of SCWs and the electromagnetic signal are considered during the solution.

In order to solve the motion problem, we pass to characteristic of $(2)[1,14]$. The characteristic of this equation is an ordinary differential equation. Since we consider the boundary problem, we pass from the time derivative to coordinate derivative using the wellknown relation for the velocity $d t=d z / \mathrm{v}_{z}$. We supplement the equation system by the equations for fast phases $p_{q, m}$. We consider that amplitudes of fields change slowly with the change of longitudinal coordinate $z$. The slow longitudinal coordinate $\zeta=z / \xi$ is used to describe slow amplitude changes. As a result, we get the equation system in standard form

$$
\begin{gathered}
\frac{d \mathrm{v}_{q z}}{d z}=\frac{e}{m_{\mathrm{e}} \gamma_{q} \mathrm{v}_{q z}} E_{z}\left(1-\frac{\mathrm{v}_{q z}^{2}}{c^{2}}\right), \\
\frac{d \zeta}{d z}=\frac{1}{\xi}, \\
\frac{d p_{q, m}}{d z}=\frac{m \omega_{1}}{\mathrm{v}_{q z}}-k_{m} \equiv \Omega_{q, m} .
\end{gathered}
$$

We compare system (5)-(7) with the standard [1, 14] and write down the vector of slow variables $\boldsymbol{x}$, vector functions $\boldsymbol{X}$, vector of fast phases $\boldsymbol{\psi}$, and vector of phase velocities $\boldsymbol{\Omega}$ in explicit form

$$
\begin{gathered}
\boldsymbol{x}=\left\{x_{\mathrm{v}_{z}}, x_{\zeta}\right\}=\left\{\mathrm{v}_{q z}, \zeta\right\}, \frac{1}{\xi} \boldsymbol{X}=\frac{1}{\xi}\left\{X_{\mathrm{v}_{z}}, X_{\zeta}\right\}, \\
\frac{1}{\xi} X_{\mathrm{v}_{z}}=\frac{e}{m_{\mathrm{e}} \gamma_{q} \mathrm{v}_{q z}} E_{z}\left(1-\frac{\mathrm{v}_{q z}^{2}}{c^{2}}\right), \frac{1}{\xi} X_{\zeta}=\frac{1}{\xi}, \\
\boldsymbol{\Psi}=\left\{\begin{array}{l}
p_{q, 1,1}, \ldots, p_{q, 1, N}, p_{2,1}, \ldots, p_{2, N}, p_{q, \alpha, 1}, \ldots, \\
p_{q, \alpha, N}, p_{q, \beta, 1}, \ldots, p_{q, \beta, N}, p_{q, \gamma, 1}, \ldots, p_{q, \gamma, N}
\end{array}\right\} \\
\boldsymbol{\Omega}=\left\{\begin{array}{l}
\Omega_{q, 1,1}, \ldots, \Omega_{q, 1, N}, \Omega_{2,1}, \ldots, \Omega_{2, N}, \Omega_{q, \alpha, 1}, \ldots, \\
\Omega_{q, \alpha, N}, \Omega_{q, \beta, 1}, \ldots, \Omega_{q, \beta, N}, \Omega_{q, \gamma, 1}, \ldots, \Omega_{q, \gamma, N}
\end{array}\right\}
\end{gathered}
$$

Further, we use the algorithm of modernized method of averaged characteristics [1,14] for the case of several fast phases. According to this algorithm we proceed to averaged variables $\overline{\mathrm{x}}$ :

$$
\mathrm{v}_{q z}=\overline{\mathrm{v}}_{q z}+\sum_{n=1}^{\infty} \frac{1}{\xi^{n}} u_{\mathrm{v}_{z}}^{(n)}(\overline{\boldsymbol{x}}, \boldsymbol{\Psi}), \zeta=\bar{\zeta}+\sum_{n=1}^{\infty} \frac{1}{\xi^{n}} u_{\zeta}^{(n)}(\overline{\boldsymbol{x}}, \boldsymbol{\Psi}) .(9)
$$
form:

Equations for slow variables have the following

$$
\frac{d \overline{\mathrm{v}}_{q z}}{d z}=\sum_{n=1}^{\infty} \frac{1}{\xi^{n}} A_{\mathrm{v}_{z}}^{(n)}(\overline{\boldsymbol{x}}), \frac{d \bar{\zeta}}{d z}=\sum_{n=1}^{\infty} \frac{1}{\xi^{n}} A_{\zeta}^{(n)}(\overline{\boldsymbol{x}}) .
$$

We restrict ourselves by the third approximation for $1 / \xi$. The algorithm of finding out $\boldsymbol{u}^{(n)}$ and $\boldsymbol{A}^{(n)}$ is known and described, e.g., in [1, 14]. Particularly from these formulas it follows that $u_{\zeta}^{(n)}=0$ for any $n ; A_{\zeta}^{(1)}=1$, $A_{\zeta}^{(n)}=0$ for $n>1 ; A_{v_{z}}^{(1)}=A_{v_{z}}^{(2)}=0$,

$$
\frac{1}{\xi} u_{\mathrm{v}_{z}}^{(1)}=\frac{e}{m_{\mathrm{e}} \overline{\mathrm{v}}_{q z}}\left(1-\frac{\overline{\mathrm{v}}_{q z}^{2}}{c^{2}}\right)^{3 / 2} \cdot \sum_{\chi}^{\alpha, \beta, \gamma} \sum_{m=1}^{N}\left[\frac{E(\bar{\zeta})_{\chi, m}}{i \Omega_{q, \chi, m}} \exp \left(i p_{q, \chi, m}\right)+c . c\right] \text {, }
$$

and so on. As a result, we obtain the solution for both the oscillating velocity component and constant velocity component (9).

The continuity equation solution is obtained in the same way as in the case of the motion problem. To solve electromagnetic field excitation problem, we substitute the expressions for the velocity (9) and the concentration of partial beams into Maxwell's equations (4). We consider that these expressions obtained using modernized method of averaged characteristics have 
the form of series with the small parameter $1 / \xi$. We also expand it in Fourier series in the fast phase harmonics. After a series of mathematical transformations, we get the system of self-consistent nonlinear differential equations for electric field strength harmonics complex amplitudes of the growing SCW in the cubic approximation

$$
\begin{gathered}
C_{2, m} \frac{d^{2} E_{m}}{d z^{2}}+C_{1, m} \frac{d E_{m}}{d z}+D_{m} E_{m}= \\
=C_{3, m}\left\langle E_{z} \cdot \sum_{m^{\prime}=1}^{N}\left[E_{m^{\prime}} \exp \left(\mathrm{i} p_{m^{\prime}}\right) /\left(\mathrm{i} m^{\prime}\right)+\text { c.c. }\right]\right\rangle_{p_{m}}+F_{m}
\end{gathered}
$$

In (11), the harmonic number index $m$ takes values from 1 to $N$,

$$
D_{m}\left(\omega_{m}, k_{m}\right) \equiv-\mathrm{i} k_{m}\left(1-\sum_{q=1}^{2} \frac{\omega_{\mathrm{p}, q}^{2}\left(1-\left(v_{q z} / c\right)^{2}\right)}{\left(\omega_{m}-k_{m} v_{q z}\right)^{2} \gamma_{q}}\right)
$$

is the SCW dispersion function, $C_{1, m}=\partial D_{m} / \partial\left(-i k_{m}\right)$,

$$
\begin{gathered}
C_{2, m}=\partial^{2} D_{m} / \partial\left(-i k_{m}\right)^{2} / 2,\left\langle\ldots>_{p_{m}}=\frac{1}{2 \pi} \int_{0}^{2 \pi}\left(\ldots \cdot \exp \left(-\mathrm{i} p_{m}\right)\right) d p_{m},\right. \\
C_{3, m}=\sum_{q=1}^{2} \frac{3 e \omega_{\mathrm{p}, q}^{2}\left(1-\left(v_{q z} / c\right)^{2}\right) k_{1}}{\operatorname{in}\left(\omega_{1}-k_{1} v_{q z}\right)^{3} v_{q z} \gamma_{q}^{2} m_{e}}\left[\frac{\omega_{1}\left(1-\left(v_{q z} / c\right)^{2}\right)}{\omega_{1}-k_{1} v_{q z}}-1\right],
\end{gathered}
$$

$F_{m}=4 \pi e<\sum_{q=1}^{2} \frac{1}{\xi^{3}} u_{n, q}^{(3)}>_{p_{3, m}}$ are the functions considering the cubic nonlinear terms and depending on the interacting waves electric field strengths. System (11) coefficients are also dependent on the constant components of velocities $v_{q}$ and concentrations $n_{q}$ of partial beams which are changing during the nonlinear interaction of SCW harmonics. Therefore, we add the equations for constant components to the system (11):

$$
\begin{aligned}
& \frac{d v_{q z}}{d z}=V_{q}\left(E_{1}, E_{2}, \ldots, E_{N}, v_{q}, n_{q}\right), \\
& \frac{d n_{q}}{d z}=N_{q}\left(E_{1}, E_{2}, \ldots, E_{N}, v_{q}, n_{q}\right) .
\end{aligned}
$$

The development of equations similar to (11), (13) is described in detail in $[1,14]$. Functions $V_{q}=\sum_{q=1}^{2} \frac{1}{\xi^{3}} A_{v_{z}, q}^{(3)}$, $N_{q}=\sum_{q=1}^{2} \frac{1}{\xi^{3}} A_{n, q}^{(3)}$ contain cubic nonlinear components.

Equation system (11), (13) allows us to investigate multiharmonic processes in helical two-stream relativistic electron beam in the framework of cubic nonlinear approximation. We should note that the task solved by the system (11), (13) is complicated enough. This system simulates models of the nonlinear dynamics of the multiharmonic SCW considering the plurality (hundreds and more) of three-wave parametric resonant interaction of dozens of harmonics and their amplification due to the two-stream instability.

\section{ANALYSIS}

We consider the situation when the two-stream instability takes place in helical relativistic two-stream electron beam. From the mathematical point of view it means that the dispersion equation for the SCW in helical two-stream beam

$$
D_{m}\left(\omega_{m}, k_{m}\right) \equiv-\mathrm{i} k_{m}\left(1-\sum_{q=1}^{2} \frac{\omega_{\mathrm{p}}^{2}\left(1-\left(v_{q z} / c\right)^{2}\right)}{\left(\omega_{m}-k_{m} v_{q z}\right)^{2} \gamma_{q}}\right)=0
$$

has complex roots. As the dispersion equations (14) analysis shows $[1,15]$, these complex solutions have the form

$$
k_{m}=\omega_{m} / v_{0 z}+\mathrm{i} \Gamma_{m},
$$

where $v_{0 z}=\left(v_{1 z}+v_{2 z}\right) / 2, \mathrm{i} \Gamma_{m}$ is the nonlinear addition to the SCW wavenumber on condition that the SCW frequency $\omega_{1}$ is much less than the critical frequency $[1,15]$

$$
\omega_{\mathrm{cr}}=\frac{\sqrt{2} \omega_{p} \sqrt{1+\gamma_{0}^{2}\left(v_{0} / c\right)^{2} \sin ^{2} \alpha}}{\delta \cdot \gamma_{0}^{3 / 2}},
$$

where $v_{0}=\left(v_{1}+v_{2}\right) / 2$ is the average velocity of the two-stream electron beam, $\gamma_{0}=1 / \sqrt{1-\left(v_{0} / c\right)^{2}}$,

$$
\delta=\frac{v_{z 1}-v_{z 2}}{v_{z 1}+v_{z 2}}=\frac{v_{1} \cos \alpha-v_{2} \cos \alpha}{v_{1} \cos \alpha+v_{2} \cos \alpha}=\frac{v_{1}-v_{2}}{v_{1}+v_{2}} .
$$

At that, maximal growth rate

$$
\Gamma\left(\omega_{\mathrm{opt}}\right)=\frac{\omega_{p} \sqrt{1+\gamma_{0}^{2}\left(v_{0} / c\right)^{2} \sin ^{2} \alpha}}{2 v_{0} \gamma_{0}^{3 / 2} \cos \alpha}
$$

belongs to the wave, which frequency corresponds to the optimal frequency $[1,15]$

$$
\begin{gathered}
\omega_{\mathrm{opt}}=\sqrt{3} \omega_{\mathrm{p}} \sqrt{1+\gamma_{0}^{2}\left(v_{0} / c\right)^{2} \sin ^{2} \alpha} /\left(2 \delta \gamma_{0}^{3 / 2}\right)= \\
=\sqrt{3 / 8} \cdot \omega_{\mathrm{cr}}
\end{gathered}
$$

The relation $\omega_{\text {opt }}=\sqrt{3 / 8} \cdot \omega_{\text {cr }}$ is right both for helical and straight two-stream relativistic electron beams.

On condition that SCW frequency is less than the two-stream instability critical frequency $\omega<\omega_{\text {cr }}$, there are two waves characterized by complex wavenumber $k_{m}$ (see the relation (15)) amongst the solutions of equation (14). One of these waves grows exponentially (amplifying wave) and $\Gamma$ has the physical meaning of growth rate for it. The other wave attenuates exponentially (evanescent wave). Since the amplitude of the evanescent wave decreases rapidly, we do not take this wave into further account. It is also worth noting that equation (14) allows two real solutions corresponding to slow and fast waves $[1,13,15]$ besides two complex solutions while $\omega<\omega_{\mathrm{cr}}$. We assume that on the input of the investigated system the amplitudes of slow and fast SCWs are small and their influence on the two-stream instability development processes can be neglected. 
It follows from (15) that plural three-wave parametric resonances occur in helical two-stream electron beam on frequencies $\omega<\omega_{\text {cr }}[1,12,13]$. Plural threewave parametric resonance occurrence is coupled with the fact consequent from (15): for the amplifying wave the coupling between the wavenumber real part and frequency is linear

$$
\operatorname{Re}(k)=\omega / v_{0 z} .
$$

It means that if the frequency of the $m^{\text {th }}$ harmonic $\omega_{m}=m \cdot \omega_{1}$ is $m$ times greater than the first harmonic frequency $\omega_{1}$, then the $m^{\text {th }}$ harmonic wavenumber real part $\operatorname{Re}\left(k_{m}\right)$ is also $m$ times greater than the first harmonic wavenumber real part:

$$
\operatorname{Re}\left(k_{m}\right)=\omega_{m} / v_{0 z}=m \omega_{1} / v_{0 z}=m \operatorname{Re}\left(k_{1}\right) .
$$

Therefore, the phase of $m^{\text {th }}$ harmonic defined by the wavenumber real part

$$
p_{m}=\omega_{m} t-\operatorname{Re}\left(k_{m}\right) z=m \cdot \omega_{1} t-m \cdot \operatorname{Re}\left(k_{1}\right) z=m \cdot p_{1}
$$

is $m$ times greater than the first harmonic phase. It leads to the fulfilment of three wave parametric resonance conditions for the plurality of SCW harmonics meeting the requirement $\omega<\omega_{\text {cr }}$

$$
p_{m_{1}}=p_{m_{2}}+p_{m_{3}}
$$

or, according to (11),

$$
m_{1}=m_{2}+m_{3},
$$

where $m_{1}, m_{2}, m_{3}$ are integer numbers. The condition (22) is realized with the vast number of harmonics, e.g. $5=3+2,5=6-1,3=4-1$, etc. Therefore, we deal with situation in which the plurality of three-wave parametric resonances (21) is realized, i.e. plural parametric resonant interactions take place. Such plural interactions are accounted in the system (11), (13). Thus, due to the linear dispersion relation plural parametric resonant interactions between SCW harmonics are realized in the system on the condition $\omega<\omega_{\text {cr. As a }}$. result of the plurality of three-wave parametric resonant interactions and also of the harmonics exponential growth because of the two-stream instability, the SCW with a broad multiharmonic spectrum forms. In this spectrum, higher harmonics have higher amplitudes than lower harmonics.

As follows from (16), (17), both critical frequency $\omega_{\text {cr }}$ and maximal growth rate $\Gamma\left(\omega_{\mathrm{opt}}\right)$ increase with an increase of the beam input angle $a$. It means that for the helical REBs having the same frequency of the main SCW harmonic, the spectrum width defined by the frequency $\omega_{1}$ and two-stream instability critical frequency $\omega_{\text {cr }}$ are larger compared with straight beams. Maximal two-stream instability growth rate is larger for helical beams than for straight ones, as follows from (17). These features of helical two-stream REBs are illustrated in Fig. 2 showing the two-stream instability growth rates dependences on frequency with different input angles $a$. These dependences are achieved through the numerical solution of (14).

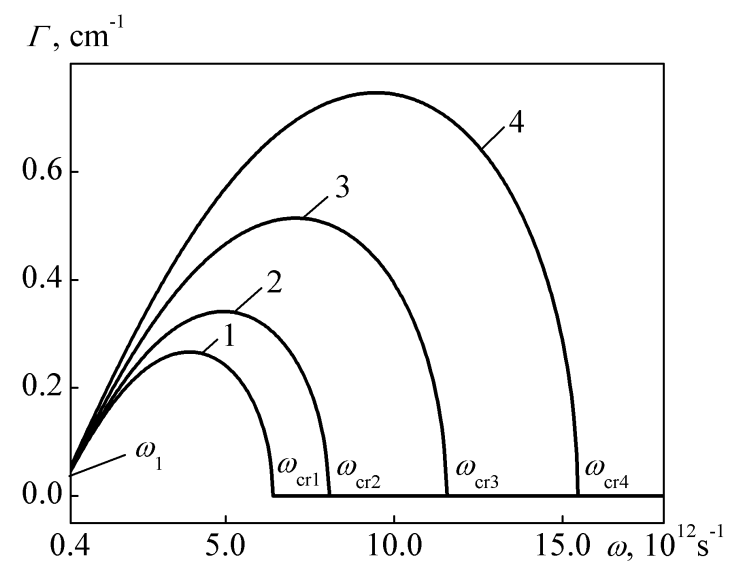

Fig. 2 - Two-stream instability growth rates as a function of frequency for different beam input angles $\alpha$

Fig. 2 is achieved for the two-stream REB with the following parameters: $\omega_{\mathrm{p} 1}=\omega_{\mathrm{p} 2}=1.5 \cdot 10^{11} \mathrm{~s}^{-1}, \gamma_{1}=4.8$, $\gamma_{2}=4.2$. Curve 1 corresponds to the case $\alpha=0^{\circ}$, curve 2 - to the case $\alpha=10^{\circ}$, curve 3 - to the case $\alpha=20^{\circ}$, curve $4-$ to the case $\alpha=30^{\circ}$. First harmonic frequency $\omega_{1}=0.4 \cdot 10^{12} \mathrm{~s}^{-1}$. When the SCW first harmonic frequency $\omega_{1}$ is much less than the critical frequency, plural three-wave parametric resonances between SCW harmonics occur in the frequency domain $\omega_{1}<\omega_{m}<\omega_{\mathrm{cr}}$. It follows from Fig. 2 that for helical two-stream beams this domain expands with increasing beam input angle $\alpha$. This means that the use of helical two-speed electron beams is preferable in multiharmonic FELs, the primary task of which is the formation of a powerful electromagnetic signal with a broad frequency spectrum $[1,12,13]$.

It also follows from Fig. 2 that two-stream instability development happens with higher growth rates in helical two-stream electron beams than in straight beams. Thus, the utilization of helical beams in TSFELs leads to the electromagnetic waves amplification rates increase. Note, that the same fact for the FELs with helical electron beams has been concluded in [5, 11], but the reason of such increase has not been indicated. It follows from the above-stated analysis that the electromagnetic signal amplification rates increase in two-stream SFELs relates to the increase of the two-stream instability in helical REBs. It is also worth noting that both twostream instability optimal frequency and critical frequency for helical electron beams are higher compared with the straight beams. It means that two-stream SFELs with helical electron beams can operate on higher frequencies than SFELs utilizing straight beams.

The dynamics of multiharmonic SCW formation in the helical two-stream REB is illustrated in Fig. 3. These results are achieved by means of (11), (13). Fig. 3a represents the spectrum of SCW electric field strength on $z=15 \mathrm{~cm}$, Fig. $3 \mathrm{~b}-$ on $z=38 \mathrm{~cm}$, Fig. $3 \mathrm{c}-$ on $z=44 \mathrm{~cm}$ for the helical beam with the input angle $\alpha=20^{\circ}$. The calculations were performed with the same parameters as in case of Fig. 2. 50 SCW harmonics were accounted during the computation $(N=50)$. On the system input $(z=0)$ the first harmonic amplitude is $10 \mathrm{~V} / \mathrm{cm}$, other harmonics are zero. As we can see, high- 
er harmonics are excited on the initial stage (Fig. 3a) of multiharmonic spectrum formation due to the plural parametric resonances. Amplitudes of these harmonics decrease with the increase of harmonic number. Next (Fig. 3b), the abnormal spectrum in which higher harmonics have higher amplitudes forms due to the twostream instability (its growth rate is different for different harmonics (see Fig. 2)). At that, not the first harmonic is maximal as in case of Fig. 3a, but the fifth harmonic. And eventually, Fig. 3b represents the formed spectrum of SCW. The frequency of the harmonic with maximal amplitude is equal to the optimal frequency $\omega_{\text {opt }}$, which corresponds to the two-stream instability maximal growth rate. On the other hand, as we can see in Fig. $3 \mathrm{~b}$, the harmonics exceeding critical frequency $\omega_{\text {cr }}$ are also excited in the system. Minimum of amplitude corresponds not to the critical frequency (29 harmonic), but to the frequency $\omega_{\min }$ (39th harmonic). There are also non-zero harmonics with frequency exceeding $\omega_{\min }$. These harmonics are improper in this frequency domain and occur due to the parametric resonance (interference) of longitudinal waves.
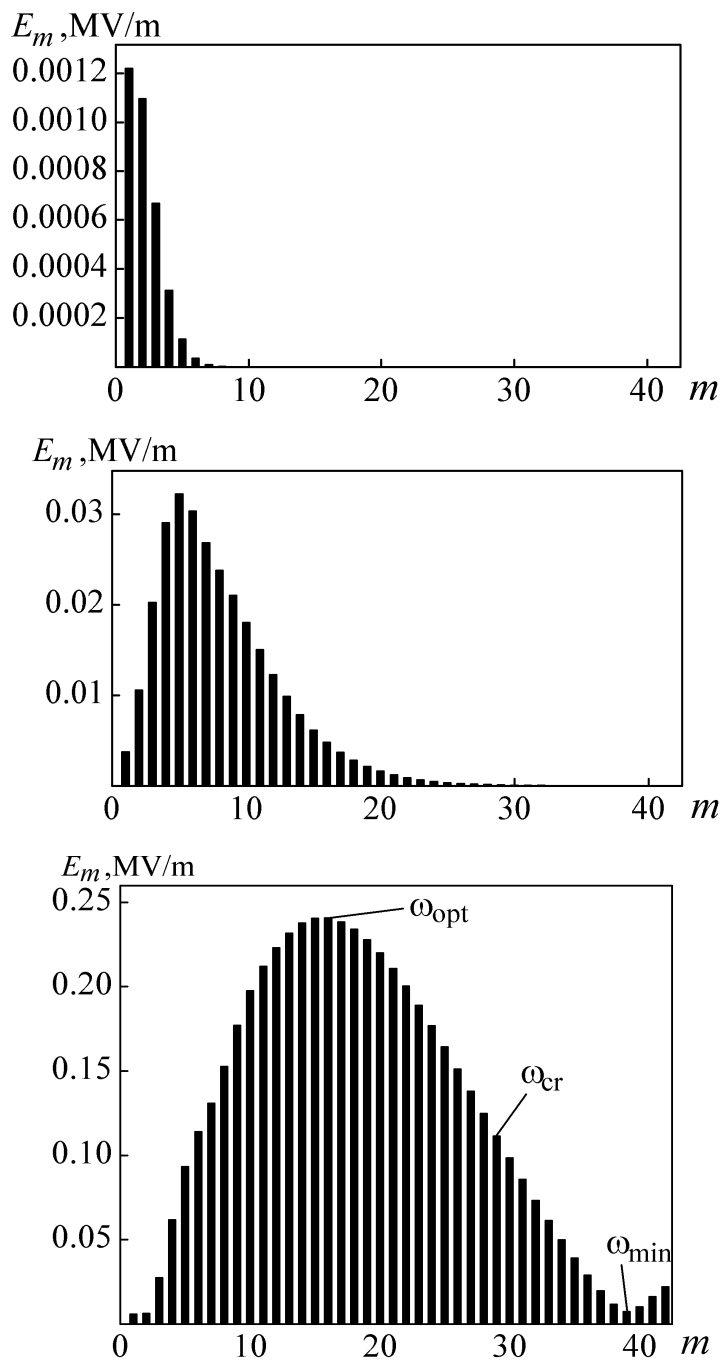

Fig. 3 - The dependence of SCW harmonic amplitudes $E_{m}$ on the frequency. First harmonic frequency $\omega_{1}=0.4 \cdot 10^{12} \mathrm{~s}^{-1}$

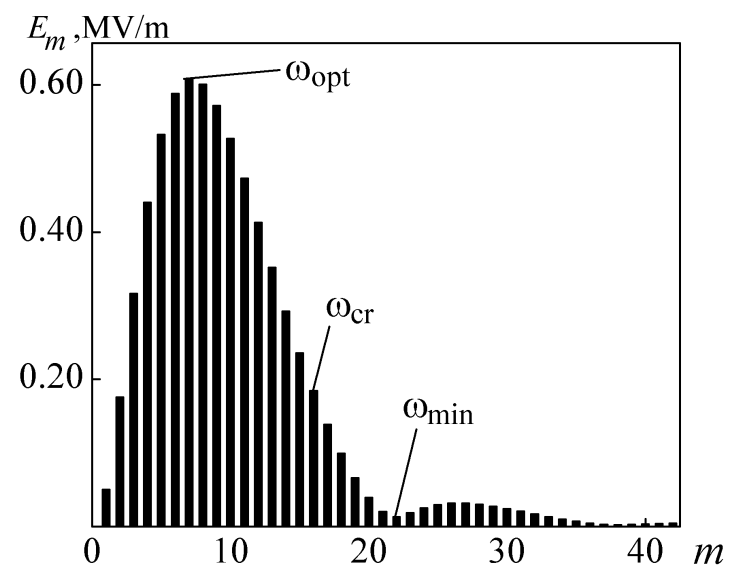

Fig. 4 - The dependence of SCW harmonic amplitudes $E_{m}$ on the frequency. Beam input angle is $\alpha=0^{\circ}$. The spectrum on $z=92 \mathrm{~cm}$ is presented. On the system input ( $z=0)$ the first harmonic amplitude is $10 \mathrm{~V} / \mathrm{cm}$, other harmonics are zero. First harmonic frequency $\omega_{1}=0.4 \cdot 10^{12} \mathrm{~s}^{-1}$. The calculations were performed with the same parameters as in case of Fig. 3

SCW spectrum in case of straight two-stream REB is different. Fig. 4 represents the SCW electric field strength spectrum for the straight two-stream REB $\left(\alpha=0^{\circ}\right)$. Calculation parameters are the same as in case of Fig. 3. Comparing Fig. 3c and Fig. 4, we can conclude that multiharmonic SCW spectrum width for helical beam is $\sim 2$ times greater than for straight beam. It can be also seen that maximal amplitude of SCW harmonic in case of straight two-stream REB is $\sim 2.5$ times less than in case of straight beam, but the harmonic number in helical REB appears to be greater.

Therefore, overall powers of multiharmonic SCWs in both cases are comparable. One should also note that helical two-stream REB forms multiharmonic SCW with higher frequency than straight REBs. Thus, average frequency of multiharmonic SCW for helical beam 2 times exceeds the average frequency of multiharmonic SCW of straight beam.

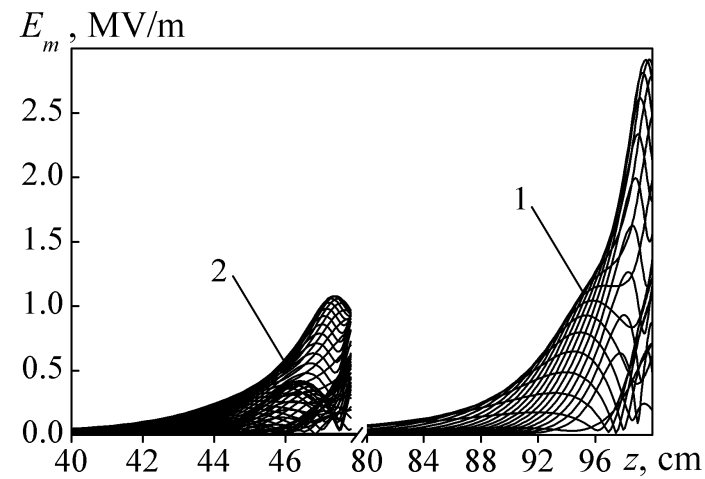

Fig. 5 - Dependence of SCW electric field strength harmonics on longitudinal coordinate $\boldsymbol{z}$ for the beam input angles $\alpha=0^{\circ}$ (curves 1 ) and $\alpha=20^{\circ}$ (curves 2)

Fig. 5 represents the dependences of 50 SCW electric field strength amplitude harmonics on longitudinal coordinate $\boldsymbol{z}$ for beam input angles $\alpha=0^{\circ}$ (curves 1) and $\alpha=20^{\circ}$ (curves 2). Calculation parameters are the 
same as in case of Fig. 3. On the input of the investigated system SCW is monochromatic with the frequency $\omega_{1}=4 \cdot 10^{11} \mathrm{~s}^{-1}$ in both cases, i.e. consists of one harmonic. It follows from Fig. 5 that electric field strength harmonics amplification rates for the helical beam (curves 2) are higher than for the straight beam (curves 1). It confirms conclusions made on the basis of (17) and Fig. 2. It also follows from these figures that saturation levels of the helical electron beam are $\sim 2.5$ times less than those of the straight beam. Based on Fig. 5, one can conclude that two-stream FELs utilizing helical electron beams can have smaller longitudinal dimensions due to the higher amplification rates compared to FELs based on straight beams.

\section{CONCLUSIONS}

Thus, we elaborated cubic nonlinear theory of plural three-wave parametric resonant interactions of SCW harmonics amplification due to the two-stream instability in the transit section of klystron-type TSFEL with helical REB. The case when the frequency of the first SCW harmonic is much less than the critical frequency of the two-stream instability was considered.

The research shows that due to the linearity of growing SCW dispersion characteristic in two-stream $\mathrm{REB}$, the three-wave parametric resonant interactions condition fulfills for the substantial number of SCW harmonics with frequency less than critical one. Due to these resonances, the multiharmonic SCW is excited and it is also amplified due to the two-stream instability. As a result, the multiharmonic SCW, which spectrum width is defined by the $1^{\text {st }}$ harmonic frequency and critical frequency $\omega_{\mathrm{cr}}$, forms.

We found that in helical two-stream REB the critical frequency increases with the increasing beam input angle at the focusing magnetic field. It means that multiharmonic SCW frequency spectrum width for helical REB increases compared with straight beam. Also, the average frequency of multiharmonic SCW for helical beam exceeds average frequency of multiharmonic SCW in a straight beam.

We demonstrated that for helical two-stream REBs growth rates are higher compared with the growth rates of straight beams. Due to this fact the saturation occurs earlier. It means that klystron-type TSFELs utilizing helical two-stream beams can have smaller longitudinal dimensions compared with TSFEL klystrons based on straight beams.

We showed that for helical two-stream REBs the multiharmonic SCW saturation levels are smaller compared with straight REBs. At that, overall energy of such wave remains comparable to the case of straight REBs due to the increase of such SCW harmonics number.

Thus, the use of helical electron beams in multiharmonic TSFELs of klystron type leads to the enhancement of their amplification characteristics, the increase of the frequency spectrum width and the frequencies of excited waves' harmonics. Longitudinal dimensions of such devices are expected to be smaller.

\section{AKNOWLEDGEMENTS}

This work was supported by the Ministry of Education and Science of Ukraine, Grant No 0117U002253.

\title{
REFERENCES
}

1. V.V. Kulish, Hierarchic Electrodynamics and Free Electron Lasers: Concepts, Calculations, and Practical Applications (Boca Raton, CRC Press: 2011).

2. W. Liu, Z. Yang, Z. Liang, Int. J. Infrared. Milli. Waves 27, 1073 (2007).

3. H. Mehdian, N. Abbasi, Phys. Plasmas 15, 13111 (2008).

4. M.H. Rouhani, B. Maraghechi, Phys. Rev. Special TopicsAccel. Beams 13, 80706 (2010).

5. N. Mahdizadeh, F.M. Aghamir, Nucl Instrum Methods Phys Res A 688, 51 (2012).

6. N. Mahdizadeh, F.M. Aghamir, J. Appl. Phys 113, 83305 (2013).

7. S. Saviz, M. Karimi, Chin. Phys. B 23, 34103 (2014).

8. T. Mohsenpour, N. Mehrabi, Phys Plasmas 20, 82133 (2013).

9. S. Nadrifard, B. Maraghechi, T. Mohsenpour, Plasma Phys. Controll. Fusion 55, 25012 (2013).

10. W. Liu, Z. Yang, Y. Wang, P. Liu, C. Zhao, IEEE Trans. Plasma Sci. 42, 42 (2014).

11. N. Mahdizadeh, J. Plasma Phys. 81, 905810612 (2015).

12. V.V. Kulish, A.V. Lysenko, M.Y. Rombovsky, V.V. Koval, I.I. Volk, Chin. Phys. B 24, 95201 (2015).

13. A. Lysenko, I. Volk, A. Serozhko, O. Rybalko, Chin. Phys. Lett. 34, 75202 (2017).

14. V.V. Kulish, A.V. Lysenko, G.A. Oleksiienko, G.V. Bychenko, O.A. Koloskova, J. Nano- Electron. Phys. 7 No 2, 02015 (2015).

15. K.-Y. Ng, Physics of Intensity Dependent Beam Instabilities (Singapore, World Scientific: 2006).

\section{Формування хвилі просторового заряду з широким частотним спектром в пролітній секції двопотокового супергетеродинного ЛВЕ клістронного типу з гвинтовим електронним пучком}

\author{
О.В. Лисенко ${ }^{1}$ Ю.Ю. Волк ${ }^{1}$ Г.А. Олексієнко ${ }^{1}$ О.О. Шматько 2
}

${ }^{1}$ Сулський державний університет, вул. Рилського-Корсакова, 2, 40007 Сули, Украӥна

2 Харківський національний університет ілені В.Н. Каразіна, площа Свободи, 4, 61022 Харків, Україна

В рамках кубічно-нелінійного наближення проведено аналіз формування хвилі просторового заряду з широким частотними спектром в гвинтових двошвидкісних електронних пучках. Показано, що формування хвилі просторового заряду з широким частотними спектром в таких пучках відбувається 
за умови, коли частота першої гармоніки такої хвилі набагато менше критичної частоти двопотокової нестійкості. Показано, що через лінійність дисперсійної характеристики зростаючої хвилі просторового заряду в гвинтовому двопотоковому релятивістському електронному пучку умова трихвильових параметричних резонансних взаемодій виконуеться для великого числа гармонік такої хвилі, частота яких менше критичної частоти. Завдяки таким резонансам відбувається збудження мультигармонічної хвилі просторового заряду, яка підсилюеться як за рахунок трихвильових параметричних резонансів, так і за рахунок двопотокової нестійкості. У підсумку формуеться мультигармонічна хвиля просторового заряду, ширина спектра якої визначаеться частотою 1-ї гармоніки і критичної частотою двопотокової нестійкості. Продемонстровано, що ширина частотного спектра мультигармонічної хвилі просторового заряду збільшуеться зі збільшенням кута вльоту електронів по відношенню до поздовжнього фокусувального магнітного поля і перевищуе ширину частотного спектра таких хвиль в прямолінійних електронних пучках. Також з'ясовано, що довжина насичення хвиль просторового заряду в гвинтових електронних пучках в два і більше разів менше, ніж в прямолінійних пучках. Тому пристрої, які використовують гвинтові двошвидкісні релятивістські електронні пучки, матимуть менші поздовжні габарити. Запропоновано використовувати гвинтові двошвидкісні релятивістські електронні пучки в мультигармонічних двопотокових супергетеродинних лазерах на вільних електрона 3 метою збільшення ширини частотного спектра, зменшення їх поздовжніх габаритів у порівнянні 3 приладами, які вживають прямолінійні електронні пучки.

Ключові слова: Двопотокова нестійкість, Двопотокові супергетеродинні лазери на вільних електронах, Гвинтові електронні пучки. 